\title{
Solar powered monitoring system development for smart farming and Internet of Thing applications
}

\author{
W. Y. Chung, R. H. Luo, C. L. Chen, S. Heythem, C. F. Chang, and C. C. Po, Y. C. Li \\ Department of Electronic Engineering, Chung-Yuan Christian University, Chung-Li, \\ Taiwan, ROC
}

This paper is mainly aimed to develop a solar powered hand-held monitoring system for real-time crop-growth multiple environment parameter sensing and ZigBee-based wireless data transmission for Internet of Thing (IoT) applications. The proposed solar powered system successfully built a Wireless Sensor Network (WSN) for quality agriculture application by using the ZigBee technology standard and TI's CC2530 chip. Commercially available sensors were utilized specifically for temperature, humidity, soil moisture, light, chlorophyll, and $\mathrm{CO}_{2}$ monitoring. With the consideration and advantages of low power, low cost and multi-node capabilities, we chose ZigBee-based wireless network to transmit data into the cloud system for further data processing and analysis. When the sensors and Zigbee transmission system are set up, the data obtained through the human machine interface on the host will be sent to the cloud database established by MySQL in XAMPP. The management and data storage of the cloud database are both processed under the phpMyAdmin system. In addition, we use another program in XAMPP - Apache HTTP Server to set up the php website. Finally, this database of the sensing information will be used for assessment and evaluation of the environmental condition, data log recording, risk management and decision making. These resources can feed back to farmer's cell phones through a decision support system. The experimental design and field test were verified in Tai-Yuan Organic farm located in TaoYuan County, Taiwan. The system will have a potential to be deployed into an open-field or green-house based farm to improve the optimized crop cultivation and increase the harvest yield.

\section{Introduction}

Smart farming becomes more important in Taiwan and the world due to major problems exist in current agricultural field such as crop damage caused by extreme climate change, problems of aging agricultural population and farmers, and domestic shortage of arable lands (1-3). So, to solve these problems by using intelligent electronics in farming becomes more popular year by year. Modern agricultural farming techniques, including crop planting environment monitoring and fertigation, can be applied to outdoor and indoor planting according to the needs of the actual field. The use of wireless monitoring systems has greatly improved the quality control required for traditional planting and large-scale farming (4-5). At present, the indoor planting of Taiwanese 
farms is mainly in the form of greenhouses and plant factories, and there are already wired power supplies. However, most conventional farms are on an outdoor bare ground, there is no power and wireless network available. In this case, other methods such as selfpowered device must be sought for collection and system development of planting environmental measurements.

Furthermore, agriculture and the development of wireless sensing as well as monitoring systems are gradually emerging. For example, more smart farming facilities are developed by using wireless transmission technology and a combination of sensors to monitor the farm's environmental parameters, such as illuminance (optical value), humidity, temperature, chlorophyll, $\mathrm{CO}_{2}$, soil moisture content and other environmental factors affecting crop growth. In addition, if agriculture and natural resources are combined and used in energy conversion, with flexible agricultural electricity is provided, the goal of green energy agriculture can be achieved. The common solar energy and wind power are often used in electric power generation. These technologies are applied to the power management of wireless sensing systems, which not only save energy but also become self-supplied power, and even can reduce power wiring problems. As shown in Figure 1, in agricultural applications, solar energy is more efficient and easier to obtain than wind power, and wind power generation is generally more suitable for windy areas or seaside. In order to enable the solar cell to provide power to the wireless sensing system, a small-scale rechargeable energy source is used to become a self-supplied wireless monitoring system to achieve a power management monitoring system.

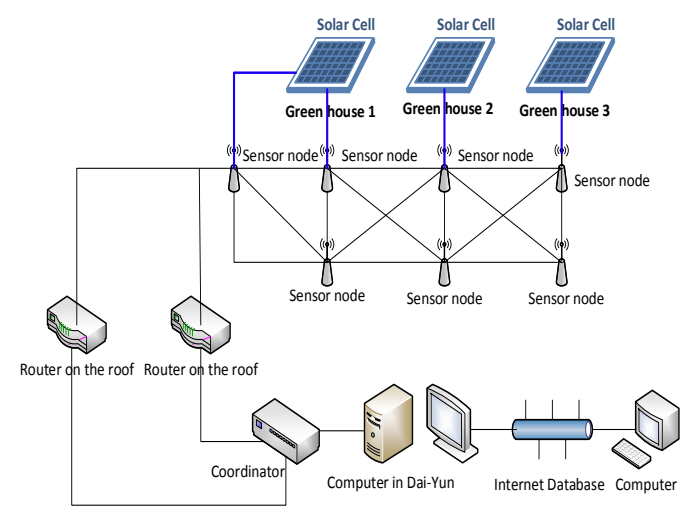

Figure 1 Solar powered sensor network for smart farming

This paper is mainly aimed to develop a solar powered hand-held monitoring system for real-time crop-growth multiple environment parameter sensing and ZigBee-based wireless data transmission for Internet of Thing (IoT) applications. The method and system development will be discussed in Section II. Field application and system performance investigation will be given in Section III. The conclusion and future work will be summarized in Section IV.

\section{Methods and System Design}

\subsection{System Development}

With the advantages to combine advanced microelectronic technology, various sensors, and internet-of-things (IoT) technology, smart farming and monitoring systems 
becomes possible for pursuing quality agriculture. The proposed system block diagram shown in Figure 2 and can be divided into four major parts: solar panel and power converter management module, sensors, transmission modules, and human machine interface. Key design concepts of each part are explored as follows:

\subsubsection{Solar cell and power management}

Through the I-V testing shown in Figure 3 by using the B1500 semiconductor analyzer, the single-crystal, single-cell solar cell $(5 \mathrm{~V} 240 \mathrm{~mA}, 90 \mathrm{~mm} 2)$ adopted in this research has measured maximum current about $101 \mathrm{~mA}$. It can be observed from the tested I- $\mathrm{V}$ curve: at $4.78 \mathrm{~V}$, the maximum power point is $101.3383 \mathrm{~mA}$ and the power is 484.397074 $\mathrm{mW}$.

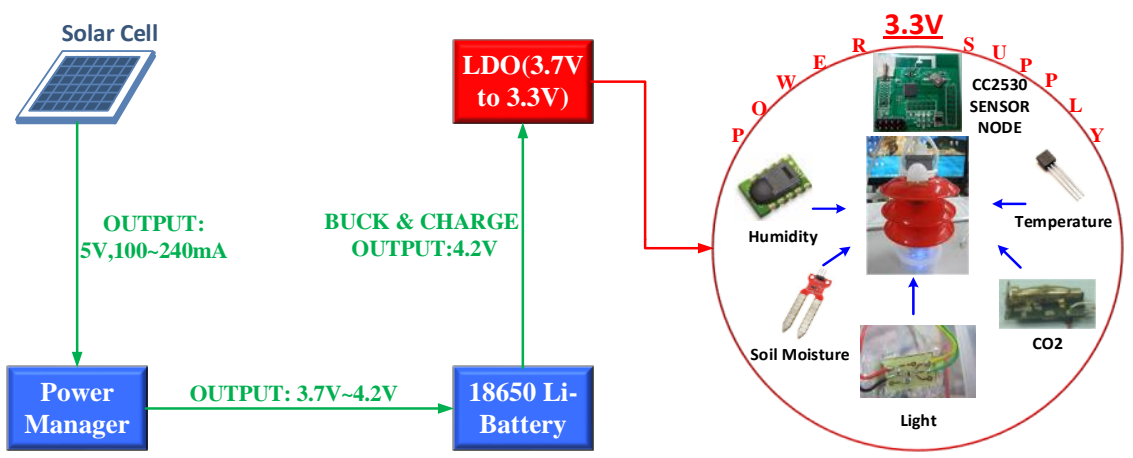

Figure 2. Block diagram of the proposed system

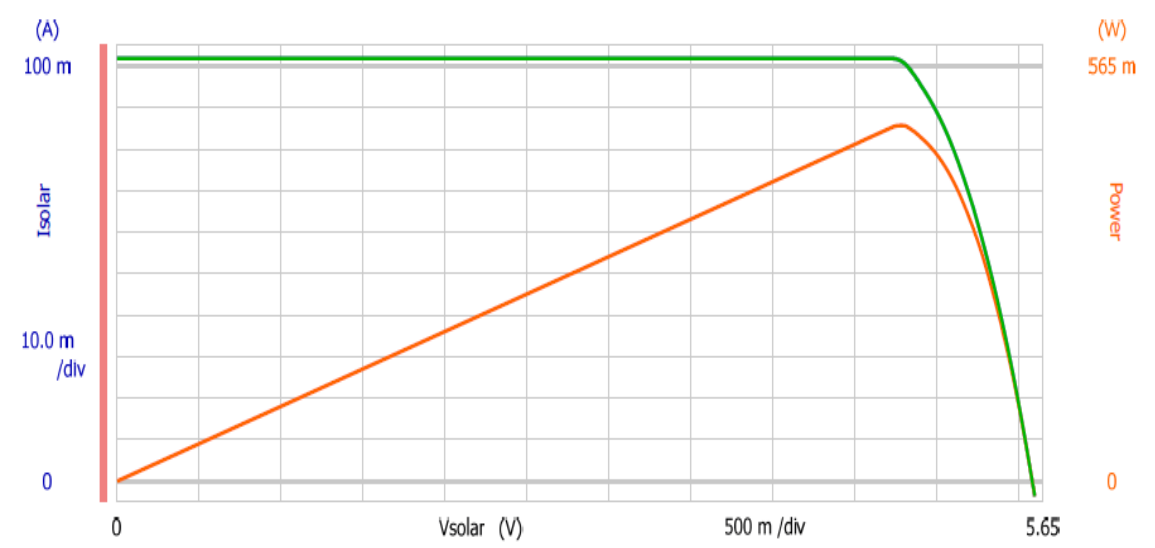

Figure 3 PV curve measurement of solar cell

In addition, to convert the efficient photovoltaic energy into electricity, we used a step-down charge management chip CN3083 to charge a rechargeable battery. This chip will adjust the charging current according to the voltage and current output by the solar panel and the voltage condition of the battery. The battery part uses an 18650 lithium battery which is the lithium niobium of NCR18650B produced by Matsushita Electric Industrial Co., Ltd. The voltage of the lithium battery under full power is $4.2 \mathrm{~V}$, and $3.7 \mathrm{~V}$ is a low voltage state, indicating that charging is required.

The back end is powered by a $3.7 \mathrm{~V} \sim 4.2 \mathrm{~V}$ battery to the designed low drop out, LDO regulator as shown in Figure 4, error amplifier can be built by commercial amplifier such 
as LM6484 or LDO component, LD1117 which converts the voltage to 3.3V required by the CC2530 and each sensor. In order to see the battery power at the monitoring interface, the voltage output of the 18650 lithium battery is simultaneously connected to the ADC of the CC2530 for power monitoring. In order to achieve energy-saving power management, the system periodically wakes up the node using the PM2 sleep mode and timer.

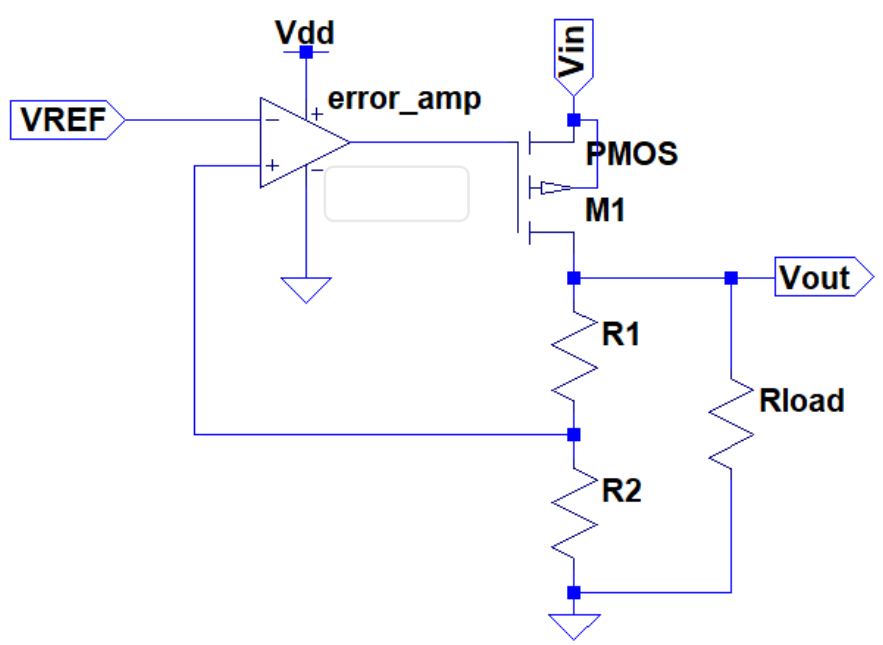

Figure 4 Core circuit of LDO regulator

\subsubsection{Multi-sensing}

Commercially available sensors were utilized specifically for temperature, humidity, soil moisture, light, chlorophyll, and $\mathrm{CO}_{2}$ monitoring. Key sensors used in the proposed system were listed in Table 1. All sensors were supplied the power from 3.3 to $5 \mathrm{~V}$. Where temperature sensor DS18B20, humidity sensor SHT10 and light sensor ISL29023 can get digital out and pass through the serial digital port processed by CC2530 module. However, more practical quantity of luminance, the light sensor has been adjusted and processed by the program to become a photon-meter (in Photosynthetic Active Radiation, PAR) which can be more efficient to observe the relationship between the optical product value and the growth of crops. Furthermore, the sensing of $\mathrm{CO}_{2}$ level is important for fruit growth monitoring, the OGM-220 carbon dioxide sensor currently used in wireless sensing nodes utilizes a gas reaction. Non-dispersive infrared spectrometer (NDIR) gas detection technology (Non-Dispersive Infra-Red, NDIR) was used (6), through a 4.26um wavelength infrared, optical pass chopper and reaction chamber. The concentration of photocurrent detection is corresponding to the $\mathrm{CO}_{2}$ level, the commonly sensing range of this $\mathrm{CO}_{2}$ sensor is from 0 to $2000 \mathrm{ppm}$, and can be up to 5000ppm.

Table 1 Crop growth environmental sensors used in this research

\begin{tabular}{|l|l|l|l|}
\hline Sensor & Vsupply (Volt) & $\begin{array}{l}\text { Operating Current } \\
\text { (Amp) }\end{array}$ & $\begin{array}{l}\text { Digital/Analog } \\
\text { Signal Output }\end{array}$ \\
\hline $\begin{array}{l}\text { Temperature/ } \\
\text { DS18B20 }\end{array}$ & $3.0-5.5$ & $9 \mathrm{~m}$ & Digital \\
\hline Humidity/ SHT10 & $2.4-5.5$ & $0.55 \mathrm{~m}-1 \mathrm{~m}$ & Digital \\
\hline Light/ ISL29023 & $2.25-3.63$ & Max. 85m & Digital \\
\hline
\end{tabular}




\begin{tabular}{|l|l|l|l|}
\hline $\begin{array}{l}\text { Soil Moisture/ } \\
\text { Fundino }\end{array}$ & 3.3 or 5.0 & $<20 \mathrm{~m}$ & Analog \\
\hline $\mathrm{CO}_{2} /$ OGM-220 & $4.5-6.5$ & $39 \mathrm{~m}-170 \mathrm{~m}$ & Analog \\
\hline $\mathrm{CC} 2530$ Chip & $2-3.6$ & $24 \mathrm{~m}-29 \mathrm{~m}$ & Analog/Digital \\
\hline
\end{tabular}

\subsubsection{Wireless transmission}

In order to reach the target of low-power transmission, the Zigbee network protocol was adopted for the wireless data transmission. The proposed system majorly formed by a CC2530 chip, the data collection of CC2530 and communication to its referred sensors are shown in Figure 5. In addition, through the design of machine human interface, graphical display shown in Figure 6 can be obtained for power efficiency monitoring.

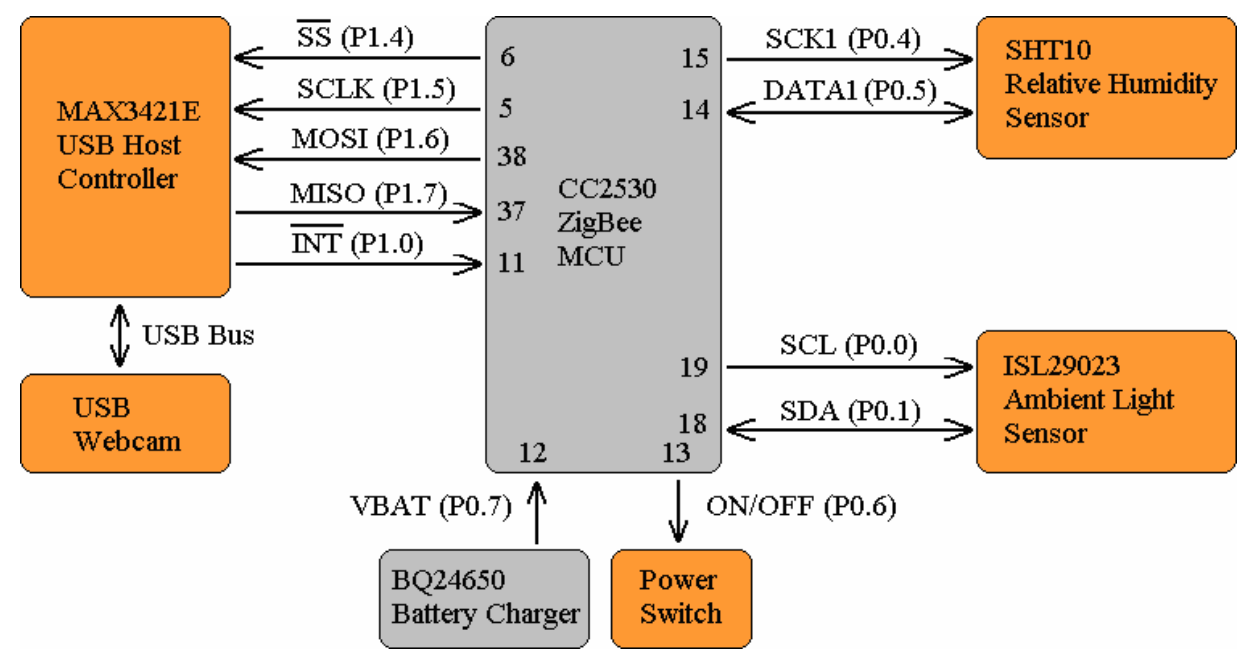

Figure 5 The referred block diagram of wireless sensor node (7)

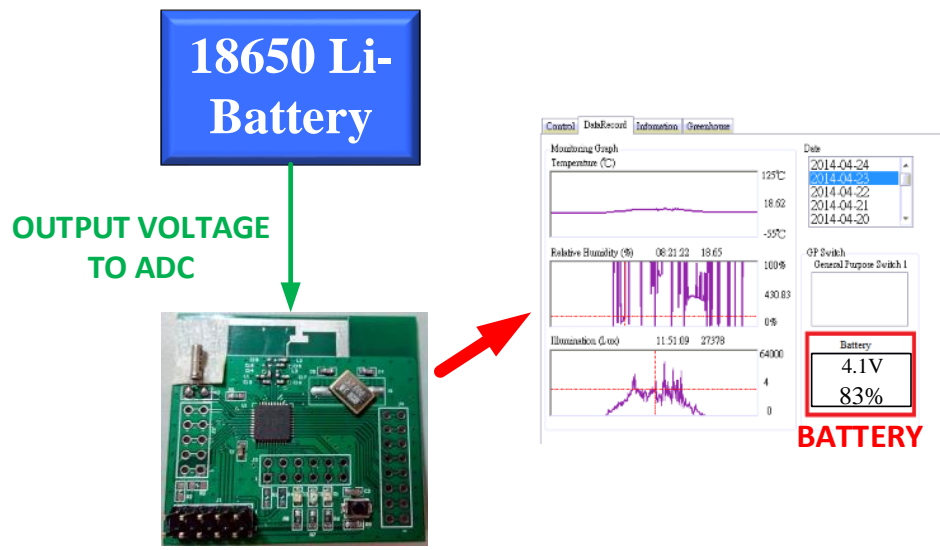

Figure 6 Graphical display for power efficiency monitoring

\subsection{System Implementation}

The system on-board module is shown in Figure 7 (a), which is the integration of specific sensors, commercial components and Zigbee based micro-controller (CC2530 
module) to verify the readout circuit design features and wireless communication. Figure 7(b) shows a more detailed functional demonstration of the system, where the microcontroller and control panel contain a liquid crystal display device, measuring button, and parameter measurement switch. It also can provide farmers a convenient hand-held device for real-time out-door plant growth monitoring applications.
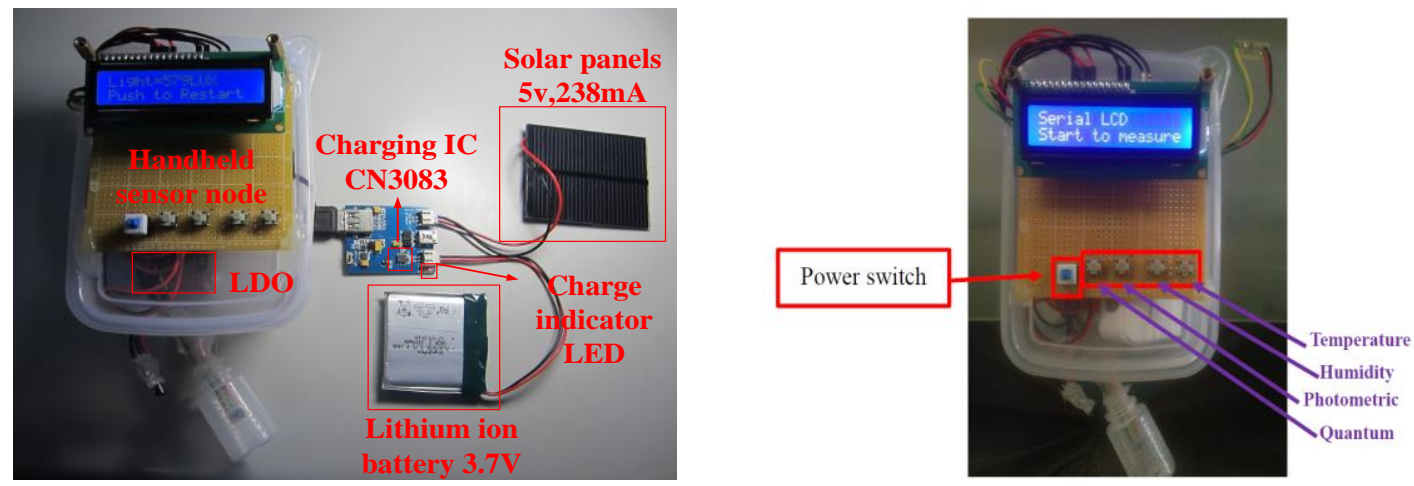

Figure 7 (a). On-board overall prototype implementation (b) On-board prototype function demonstration

\section{Results and Discussion}

\subsection{Real Field Sensing Results}

The experimental design and field test as shown in Figure 8 (a) and (b) were verified in Tai-Yuan Organic farm located in Tao-Yuan County, Taiwan, the Zigbee network was managed in mesh architecture through many end devices, routers, and coordinator structure. Three of 120 green houses were chosen as experimental fields for different environmental setting conditions such as luminance make-up by LED panel or project light after sun set. The hand-held and solar powered device was also successfully linked with wireless sensor node network.
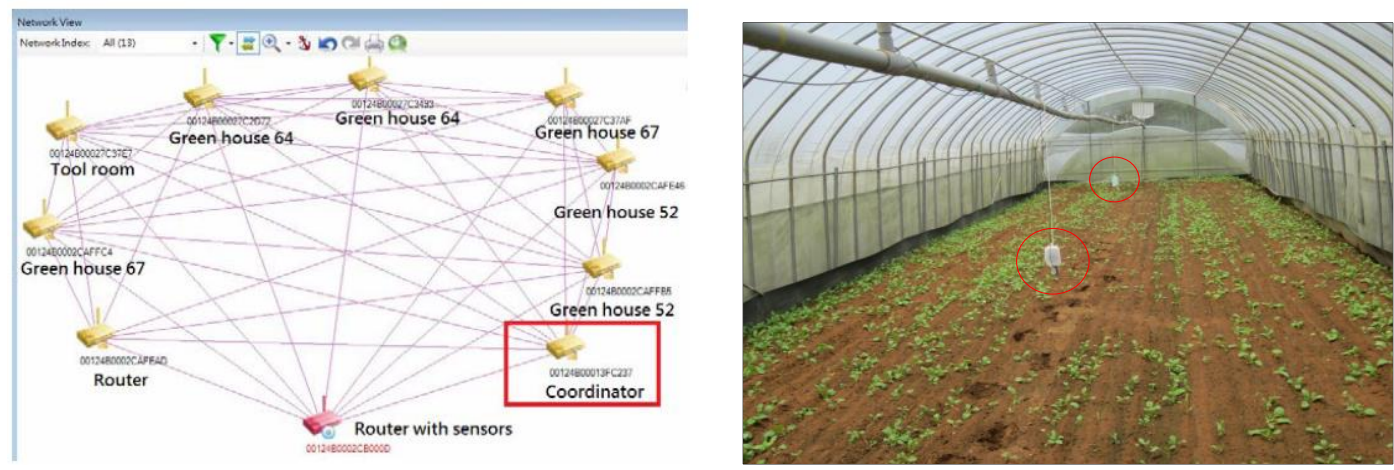

Figure 8 (a) Zigbee-based sensor network. (b) Real field sensing node setup

Based on the power consumption of CC2530 module used in all wake-up mode and data transmission, the charged power of one-single 18650 lithium battery powered handheld system can be maintain normal function up to 5 days. The average current consumed shown in Figure 9 is around $27.3 \mathrm{~mA}$ when CC2530 module served as a router role. 


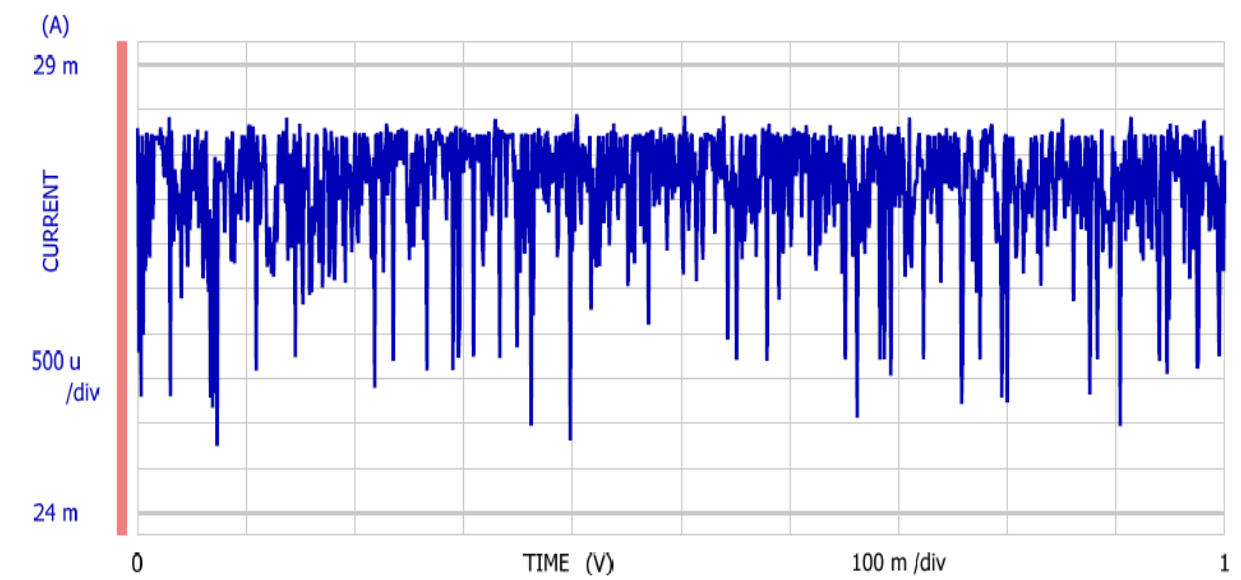

Figure 9 Test results of CC2530 current consumption as a router (100 seconds)

\subsection{Data Acquisition and Control System}

By using the open-source environment and based on the system architecture set up as shown in Figure 10 (a), when the sensors and Zigbee transmission system are set up, the data obtained through the human machine interface on the host will be sent to the cloud database established by MySQL in XAMPP. The management and data storage of the cloud database are both processed under the phpMyAdmin system. In addition, we use another program in XAMPP - Apache HTTP Server to set up the php website. Finally, this database of the sensing information as shown in Figure 10 (b) will be used for assessment and evaluation of the environmental condition, data log recording, risk management and decision making. These resources can feed back to farmer's cell phones through a decision support system.
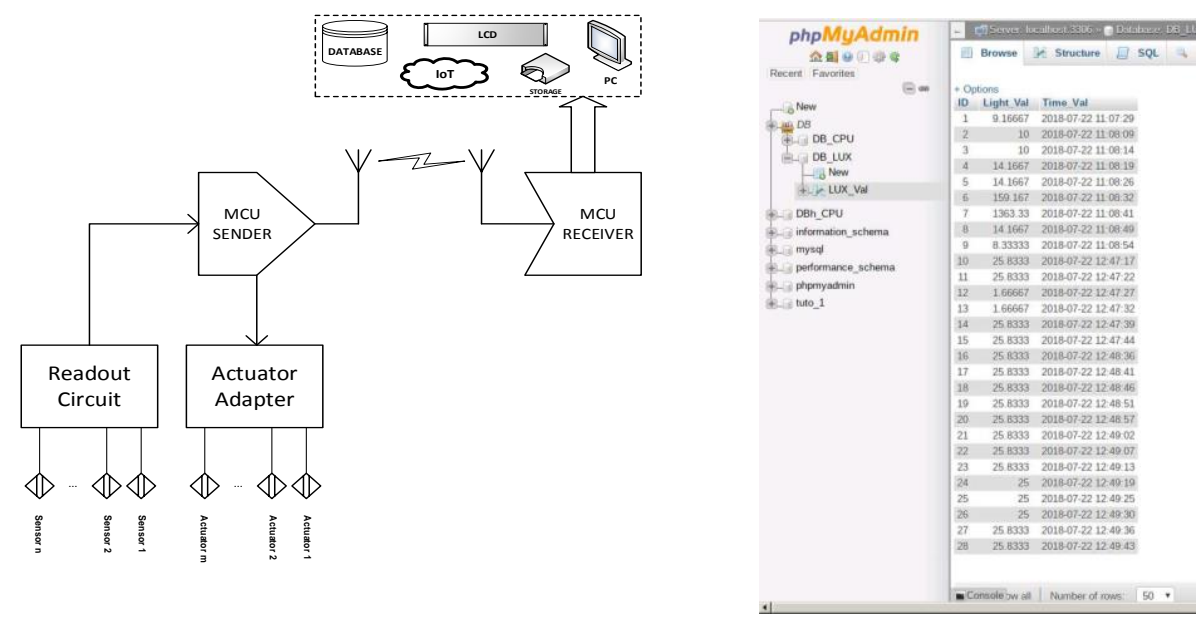

Figure 10 (a) Data acquisition and control diagram. (b) Display of MyAdmin screen

\section{Conclusion}

This paper successfully proposed a hand-held solar-powered multi-parameter monitoring system for the potential smart framing applications. The research build a selfsufficient powered and ZigBee based wireless sensing and power management system. We also applied solar cells and power management chips to optimize the power usage of 
ZigBee nodes; in addition, it can solve the power wiring problems. The test results of the proposed system and wireless transmitted data show the acceptable and promising performance referred to corresponding meters for individual parameter sensing.

For the future work, we will continuously focus on sensing hub network design and implementation, further database setup and big data analysis for more large-scale farmlands' managements and efficient crop cultivation.

\section{Acknowledgments}

The authors would like to acknowledge the Ministry of Science and Technology Taiwan, (MOST 106-2218-E-033-006-MY2) for the project funding; the field tests supported by Tai-Yuan Organic farm and Bau-Sui farm, Tao-Yuan City; Tao-Yuan District Agricultural Research and Extension Station, COA and National Center for HighPerformance Computing as well as National Chip Implementation Center, Taiwan, ROC for the technical support.

\section{References}

1. Agriculture Index, Council of Agriculture, Executive Yuan, Agriculture Statistic Information, URL http://agrstat.coa.gov.tw/sdweb/public/indicator/Indicator.aspx (2019).

2. Agriculture Policy, Council of Agriculture, Executive Yuan, Agriculture Statistic Information, URL https://www.coa.gov.tw/ws.php?id=3 (2019).

3. Consultation Document, "The New Agricultural Policy: Sustainable Agricultural Development in Hong Kong" Food and Health Bureau Agriculture, Fisheries and Conservation Department (2014).

4. Zhang, Z.; "Design of greenhouse monitoring system based on ZigBee," IEEE $2^{\text {nd }}$ Conference on Artificial Intelligence, Management Science and Electronic Commerce (AIMSEC), Dengleng, China, (2011)

5. Zhao, C; et. al; "The Study and Application of the 1OT Technology in Agriculture," 3rd International Conference on Computer Science and InformationTechnology, (2010)

6. https://www.orisystech.com/upload/files/OGS-401F2 R6.pdf (2019).

7. C. L. Chen, "A Wireless Sensor Network Design and Application for Greenhouse Monitoring System” Master Thesis, Chung-Yuan Christian University (2011) 